\title{
Chapter 6 \\ Perceived Social Support Network \\ and Achievement: Mediation \\ by Motivational Beliefs and Moderation \\ by Gender
}

\section{Emmanuel Adu-tutu Bofah and Markku S. Hannula}

\begin{abstract}
Research has shown that perceived social support (PSS) (from parents and teachers) influences achievement. However, little is known about how this relationship operates. This study examines the multiple mediational effects of students' motivational beliefs in relationship to the association between PSS and mathematics achievement. The sample included the African countries that participated in the TIMSS 2011 (Ghana, Botswana, South Africa, Morocco, and Tunisia). A bootstrap analysis indicated a unique pattern of the role of motivational beliefs in mediating the relationships between PSS and achievement. Moreover, gender was found to moderate the indirect effect in some countries. The findings indicate that total mediation effect of students' motivational belief on the relationship between PSS and achievement is "culture-fair but not culture-free".
\end{abstract}

Keywords Social support $\cdot$ Motivational beliefs $\cdot$ Gender $\cdot$ Multiple mediation • Moderated mediation $\cdot$ Mathematics achievement

\subsection{Introduction and Background}

African countries face an endemic problem such as low achievement in mathematics, mathematics-related motivational beliefs and enrolment in mathematics related programs (Gerdes, 1998). An emerging consensus exists in mathematics education literature about what contributes to students' academic success. Research has indicated that achievement in mathematics is a function of many interrelated variables such as socioeconomic, social support (from peers, parent, and teachers), and motivational

E. A. Bofah $(\varangle) \cdot$ M. S. Hannula

University of Helsinki, Helsinki, Finland

e-mail: emmanuel.bofah@hotmail.com; ebofah72@gmail.com

M. S. Hannula

e-mail: markku.hannula@helsinki.fi

M. S. Hannula

Volda University College, Joplassvegen 11, 6103 Volda, Norway

(C) The Author(s) 2019

M. S. Hannula et al. (eds.), Affect and Mathematics Education,

ICME-13 Monographs, https://doi.org/10.1007/978-3-030-13761-8_6 
beliefs. Conditions such as perceived social support (from parent, teachers and peers) and motivational beliefs have been known and discussed extensively and proven empirically (Ahmed, Minnaert, van der Werf, \& Kuyper, 2010; Eccles[Parsons] et al., 1983; Mutodi \& Ngirande, 2014).

Understanding the role of motivation and social support on achievement in mathematics has attracted serious attention in recent years. However, extant literature suggest that the presence of social support (or lack thereof) may lead to positive or negative affective disposition, which in turn influences achievement (Ahmed et al., 2010; Bofah \& Hannula, 2015; Eccles[Parsons] et al., 1983; Eccles, 2007; Roeser, Eccles, \& Sameroff, 2000; Rosenfeld, Richman, \& Bowen, 2000).

The concept of motivation stands at the center of achievement. Theories of motivations such as the Expectancy-value theory (EVT) have treated motivation as a concept that varies in amount whereas others theories such as the self-determination theory place emphasis on the type of motivation rather than the amount (Ryan \& Deci, 2000). Ryan and Deci (2000) have theorized motivation to include extrinsic and intrinsic motivation and indicated that motivation is influenced by the "response to what the social environment affords" (Ryan \& Deci, 2009, p. 175).

In the EVT model (Eccles[Parsons] et al., 1983), motivational beliefs such as intrinsic value and utility value or value beliefs have been discussed as predictors of performance and choice.

Intrinsic value is the enjoyment someone achieve from doing a given task; the task is an end to itself - the task must be intrinsically rewarding, and this notion have been discussed to be similar to the concept of intrinsic motivation by Ryan and Deci (2009). Moreover, Intrinsic value has been linked to the construct of individual interest, enjoyment and liking (Gaspard et al., 2015, p. 664), hence the term like to be synonymous to intrinsic motivation in the present study.

Value beliefs captures more "extrinsic" or the usefulness of engaging in a certain task for short- and long-term goals (Gaspard et al., 2015, p. 664). As Gaspard et al. (2015) indicate: "the task is a means to an end rather than an end in itself" (p. 664). In other words, value beliefs or usefulness refers to how a task fits into an individual's future plans, for instance, taking a mathematics class to fulfill a requirement for a science degree (Wigfield \& Cambria, 2010). Value beliefs, is thus instrumental in nature and tied to extrinsic motivation (see Ryan \& Deci, 2000, 2009 for further discussion).

Several arguments have been discussed in the literature concerning motivational belief and achievement. One argument is that the complex relationship between motivational belief and achievement could be best understood under wider social and psychological settings in which it operates (Bronfenbrenner, 1979; Eccles[Parsons] et al., 1983). Perception of social support that adolescents receive from significant others have been known to facilitate adaptive behaviors in most academic domains (Cutrona, Cole, Colangelo, Assouline, \& Russell 1994). Parents, teachers, and peers are major sources of support during adolescence. Most often, studies assess perceived social support from these social network agents using a single construct (cf. Ahmed et al., 2010; Wentzel, 1998) without distinguishing each support unit. However, each support source may influence motivation and achievement differently depending on 
the measurement model. Moreover, the psychological mechanism through which social support (from teachers, parents and peers) influence academic achievement may be different for each different source. For instance, Wentzel (1998) showed that academic motivation such as interest and achievement goal mediates the relationship between social support and academic performance (composite final grades in English, science, social studies, and mathematics). Ahmed et al. (2010) found that motivational measures like competence, importance, enjoyment (including interest), and anxiety significantly mediate the associations between social support (from teachers, parents, and peer) and achievement.

However, most of these studies primarily was conducted with Western educational sample and settings. Moreover, the relationship between motivation and achievement might be moderated by culture values (Meece, Glienke, \& Burg, 2006; Rosenfeld et al., 2000). Evidence indicates that students with higher extrinsic motivation show lower academic achievement in some countries (Marsh et al., 2013), but not in others (Bofah \& Hannula, 2015; Chiu \& Chow, 2010). Our present sample, which is a national representation of five African countries, will help incorporate cross-cultural perspectives into the previous research, thus will help test the generalizability of the previous findings. This can help challenge the foundations of current theories and provide ways to improve upon it.

Gender differences in motivational beliefs and mathematics achievement have received a lot of attention in the literature on mathematics education. Many social and cultural barriers influence gendered motivational beliefs and achievement. These barriers vary across and within countries, but generally the influences on girls are significant (Chaman, Beswick, \& Callingham, 2014). Studies have argued that gender differences in motivational beliefs and mathematics achievement are culture-specific (Forgasz, Leder, Mittelberg, Tan, \& Murimo, 2015; Hyde \& Mertz, 2009). Other studies have indicated that, mathematics-achievement gap "is due, in a large part, to sociocultural and other environmental factors" (Hyde \& Mertz, 2009), and “... the fact that girls' progress in mathematics has been improving over time, even though boys still perform better, suggests that mathematics ability is not innate but susceptible to social influences and instruction" (Stromquist, 2007, p. 37). Studies have shown that in some countries (e.g., gender-equal cultures) girls have reached parity with boys in mathematics performance (Hyde, Fennema, \& Lamon, 1990; Hyde, Lindberg, Linn, Ellis, \& Williams, 2008; Hyde \& Mertz, 2009), a pattern that is not found in some other nations (Bofah \& Hannula, 2015).

Research on gender differences in motivational beliefs (like and values of mathematics) have yielded inconsistent outcomes. Some reported higher values for boys in Germany (Gaspard et al., 2015; Marsh, Trautwein, Lüdtke, Köller, \& Baumert, 2005), whereas other studies reported no differences in the United States (Eccles, Wigfield, Harold, \& Blumenfeld, 1993; Jacobs et al., 2002; Wigfield et al., 1997). In general, “... girls perceive mathematics as a subject of importance in the school context but also perceive it as personally unimportant and unrelated to their future plans" (Gaspard et al., 2015, p. 672). With like mathematics, males have been found to report higher liking for mathematics in Germany as well as Australia (Frenzel, Pekrun, \& Goetz, 2007; Gaspard et al., 2015; Watt, 2004; Watt et al., 2012). In Australia, 
Thomson, Hillman, and Wernert (2012) reported evidence from the 2011 Trends in International Mathematics and Science Study (TIMSS 2011) that boys were more likely than their female peers to like mathematics, and value it. They further noted a positive relationship between these measures and mathematics performance on the TIMSS assessment.

Modern expectancy-value theory (EVT; Eccles[Parsons] et al., 1983) is a useful framework for conceptualizing the relationship between achievement, motivational beliefs and gender. The theory proved to be highly effective in explaining gender differences in achievement. EVT indicates that motivational beliefs are important factors in explaining gender differences in academic choices (Eccles, 2009).

The present study expands the present literature and examines the unconditional or mediational role of students' motivational belief measures such as the "like mathematics", and the value of mathematics on the relationship between perceived social support network (PSS: from parents and teachers) and achievement in an African context. Specifically, we tested the cultural specificity associated with the mechanism through which perceived social support from parents and teachers influence achievement jointly by students' motivational belief measures (e.g., Like and value mathematics). The study also examines whether students' gender moderates the indirect effect of PSS on achievement through their motivational beliefs. To date, no study has examine the moderated mediation of gender in the relationship between PSS and achievement via motivational belief using TIMSS in the African context. The hypothesized multiple mediation or unconditional model (panel A; statistical form in panel B) and the moderated mediation or conditional model (panel C; statistical form in panel D) is presented in Fig. 6.1. The study used multiple mediators because a single motivational measure cannot explain the complex interplay between social support network and achievement (Preacher \& Hayes, 2008).

\subsection{Method}

\subsubsection{Study Design and Analysis}

The present study is based on the TIMSS 2011 across the five participating African countries (Ghana, Botswana, South Africa, Morocco and Tunisia) (see Table 6.1). The study used the Mplus version 7.4, involving latent variable models together with Mplus complex survey design option to control for the clustered design and adjusted standard errors. 

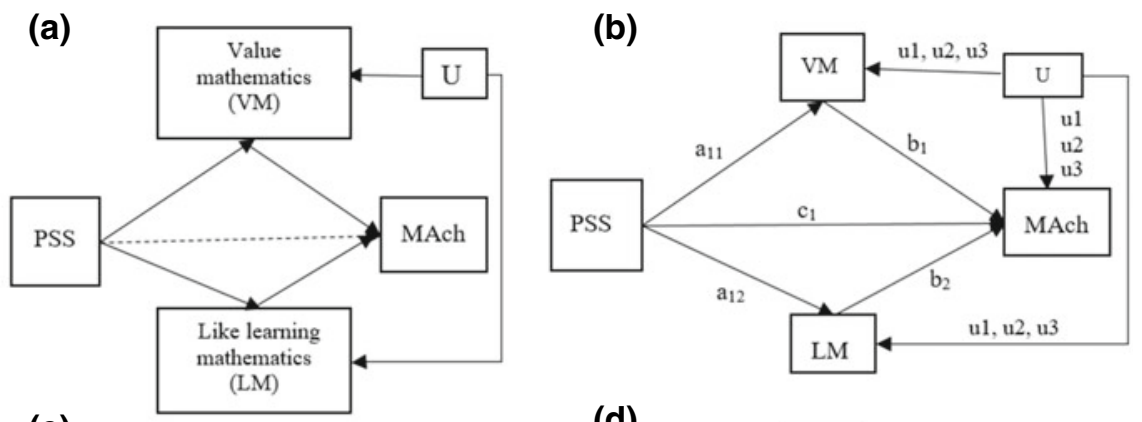

(c)
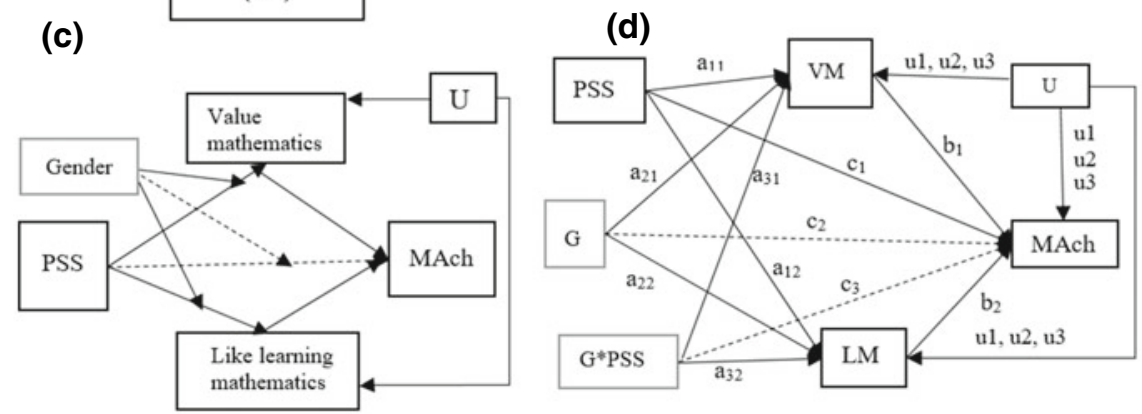

Fig. 6.1 The conceptual multiple mediation model (panel A) and a moderated multiple mediation (panel C) model in conceptual form. Panel B and panel D translate into a statistical model for panel A and C respectively. $G$ gender; PSS perceived social support (from teachers and parents); MAch mathematics achievement, $L M$ like learning mathematics, $V M$ value mathematics, u1-u3 indicates the covariates: parental education (u1), Long-term educational aspirations (u2), weekly time spent on mathematics homework (u3). Dotted lines represent optional moderator effects which can be included without affecting the estimates of the index of moderated mediation provided in the text

Table 6.1 Sample breakdown and characteristics

\begin{tabular}{l|l|l|l|l|l|l}
\hline Country & N & $\begin{array}{l}\text { Girls } \\
(\%)\end{array}$ & Schools & $\begin{array}{l}\text { Clusters } \\
\text { (intact } \\
\text { classes })\end{array}$ & $\begin{array}{l}\text { Average class } \\
\text { size }\end{array}$ & Grade \\
\hline Ghana & 7323 & 48 & 161 & 173 & 41 & 8 \\
\hline Morocco & 8986 & 48 & 279 & 279 & 32 & 8 \\
\hline Tunisia & 5128 & 51 & 207 & 207 & 25 & 8 \\
\hline Botswana & 5400 & 49 & 150 & 151 & 35 & 9 \\
\hline South Africa & 11,969 & 49 & 285 & 317 & 37 & 9 \\
\hline
\end{tabular}




\subsubsection{Participants}

The participants in this study are the students from the five African countries (Botswana, Ghana, South Africa, Morocco, and Tunisia) that participated in the TIMSS 2011 study (see Table 6.1). Sample involved 38,806 students (49.2\% girls) from 989 intact classrooms (clusters) with an average of 39 students per class.

\subsubsection{Measures of Social Support and Mathematics Achievement}

Each support measure includes four items on a four-point scale. This measure asks students to indicate their perception about how their parents and teachers show supportive behaviors such as caring, understanding, responsiveness and guiding them in the learning of mathematics. An example item of the perceived parental support is "my parents ask me what I am learning in school". An example item of the perceived teacher support construct is "My teacher is easy to understand". The construct reliability and validity have been established in several studies (see Bofah, 2015, 2016; Bofah \& Hannula, 2015).

TIMSS reported students' mathematics achievement in five plausible values (see Foy, Brossman, \& Galia, 2013 for scaling and proficiency estimation with plausible values). All five plausible values were used in the mediation analysis but, due to computational challenges associated with combining multiple imputation and bootstrapping, one plausible value was randomly selected for the moderated mediation analysis.

\subsubsection{Mediating and Moderating Variables}

Motivation has been discussed in the literature as a measure of intrinsic (i.e., the students like learning mathematics scale (LM)) and extrinsic (i.e., the students value mathematics scale (VM)) motivation (Ryan \& Deci, 2000). In the present study, measures of the motivational beliefs included two measures: the "students' value mathematics" scale and the "students like learning mathematics" scale. For easy reading, we use the terms value of mathematics and like mathematics, to mean the students value mathematics scale (VM), and the students like learning mathematics scale (LM) respectively. There were six items on the VM scale and five items on the LM scale both rated on a 4-point Likert type scale. An example item for like mathematics is "I like mathematics" and sample item for value mathematics is "I need to do well in mathematics to get the job I want". The reliability of the mediator(s) have been shown to be reliable and valid in previous studies (Bofah, 2015, 2016; 
Bofah \& Hannula, 2015). Gender was the moderating variable and was coded ' 0 ' for female and ' 1 ' for male.

\subsubsection{Control Variables}

We added some additional variables to assess the vulnerability of our findings. Consistent with previous research, parental education (Bronfenbrenner, 1986), weekly time spent on mathematics homework (Singh et al., 2002), and students long-term educational aspirations (Bofah, 2015; Bofah \& Hannula, 2015) were statistically controlled and entered into the model as covariates.

\subsubsection{Statistical Approaches to the Hypothesised Model}

Mplus software version 7.4 (Muthén \& Muthén, 1998-2015) was used to test all the hypothesised model. To account for the non-independence of the student data, model parameters were estimated by means of the Mplus robust maximum likelihood estimator (MLR) in combination with the "complex" option. Sampling weights were taken into account (weighting variable supplied with the data). We used the Mplus multiple imputation procedure with five imputed data set, combining the results of the five sets of plausible values using Rubin (1987) formulas.

We used a latent variable framework to provide estimates of country differences taking into account the multiple indicators, measurement errors, and the complex structural relationships associated with the variables as well as account for the low reliabilities so as not to inflate the estimates.

Because the structural model includes latent variables, there was the need to ascertain the validity of the measured constructs, by examining the psychometric properties. Once the measurement model adequately fit the data, then one can confidently examine the structural model. In the present study, confirmatory factor analyses (CFAs) were conducted for the perceived support and mediational constructs together. We control method effect associated with the use of negatively phrased item in surveys by allowing the correlated uniqueness of the two negatively phrased items on the "like mathematics" construct to covary (see Bofah \& Hannula, 2015).

Most research on cross-cultural comparison advocates the use of measurement invariance to ease cross-cultural generalizability (Bofah, 2016; Bofah \& Hannula, 2015; Little, 1997; Steenkamp \& Baumgartner, 1998; Vandenberg \& Lance, 2000). Since country differences can only be properly examined if the same constructs are measured for the five countries, multiple-group factor-analytic models were applied (Little, 1997; Lubke, Dolan, Kelderman, \& Mellenbergh, 2003; Sass, 2011). This involved using multiple-group factor-analytic models to examine whether the model showed the appropriate level of measurement invariance between countries. If measurement invariance does not hold, any inference drawn about group differences 
may be flawed or meaningless (Little, 1997; Lubke, Dolan, Kelderman, \& Mellenbergh, 2003; Sass, 2011). There are several levels of measurement invariance. Two levels are of significance in this study and cross-cultural comparison in general if factor mean comparison across groups or countries is not the focus. The two levels are: configural, and metric (also referred to as factor loading invariance) invariance. In testing measurement invariance across groups, a series of hierarchical stepwise operations based on multiple-group factor analytic models in a logically defined and increasingly restrictive models are tested (Byrne, 2010). Before examining the hypothesized model, test of invariance of the measurement construct for each country was constructed. Support for configural invariance indicates that factors are similar across groups. On the other hand, support for factorial invariance indicates that the constructs are on the same scale and any differences in variation of the measured variable are due to latent variables (Keith, 2015). It is thus possible to compare the structural paths in our structural model.

\subsubsection{Mediation and Moderation Analysis}

The analysis was done separately for each perceived support unit (teacher and parent). For computational accuracy, the unconditional model (i.e., mediation or indirect effect model) and the conditional model (i.e., moderation mediation) were estimated separately for each support source (Preacher, Rucker, \& Hayes, 2007).

Mediation, or an indirect effect, is said to occur when the causal effect of an independent variable $(\mathrm{X})$ (here, perceived social support (PSS: from parents and teachers) on a dependent variable (Y) (MAch: mathematics achievement in this case) is transmitted via a mediator or intervening variable $(\mathrm{M})$ (motivational belief: value or like mathematics in this study) (Preacher \& Hayes, 2008). Figure 6.1 illustrates a scenario involving multiple mediators (e.g., value mathematics (VM) and like mathematics (LM)). This figure serves as the theoretical model for the study. In Fig. 6.1, panel A is the conceptual model and panel B is the statistical model. In the statistical model, the effect of PSS on mediators VM and LM are designated as $\mathrm{a}_{11}$ and $\mathrm{a}_{12}$ respectively, the effect of VM on Y as $\mathrm{b}_{1}$, LM on Y as $\mathrm{b}_{2}$, and the effect of PSS on MAch as $c_{1}$. The effect of PSS on Y is called the direct effect $\left(c_{1}\right)$. The indirect effect of PSS on MAch via the mediator(s) is defined as the product of the two paths linking PSS to MAch via that mediator. In Fig. 6.1b (panel B), the specific indirect effect of PSS on MAch through VM and LM is quantified as $\mathrm{a}_{11} \times \mathrm{b}_{1}$ and $\mathrm{a}_{12} \times \mathrm{b}_{2}$ respectively. The total indirect effect of PSS on MAch is the sum of the specific indirect effects (i.e., $a_{11} b_{1}+a_{12} b_{2}$ ), and the total effect (often represented as c) of PSS on MAch is the sum of the direct effect $\left(c_{1}\right)$ and the total indirect effects $\left(a_{11} \times b_{1}+a_{12} \times b_{2}\right)$ (i.e., $\mathrm{c}=\mathrm{c}_{1}+\mathrm{a}_{11} \times \mathrm{b}_{1}+\mathrm{a}_{12} \times \mathrm{b}_{2}$ ). In Fig. 6.1 panel $\mathrm{B}$, coefficients $\mathrm{a}_{11}$ and $\mathrm{a}_{12}$ represent the effects of social support on value and like mathematics, respectively, whereas coefficients $b_{1}$ and $b_{2}$ represent the effects of mediator(s) value and like mathematics on achievement after controlling for the effect of social support respectively. As indicated in both the conceptualized and statistical model we controlled for parental education, students' long-term educational aspirations and weekly time spent on 
mathematics homework. The terms mediation and indirect effect will be used loosely and somewhat interchangeably in this paper.

Moderated mediation occurs when the strength of an indirect effect depends on the level of some variable, or in other words, when mediation relations are contingent on the level of a moderator (gender in this study) (Preacher et al., 2007, p. 193). As Edwards and Lambert (2007, p. 6) indicated “...moderated mediation means that either or both of the path $X$ to $M$ and from $M$ to $Y$, which constitute the indirect effect of $X$ to $Y$, vary across levels of the moderator variable $\mathrm{V}$ (say gender)". Different forms of moderated mediation exist in the literature depending on the number of mediators as well as path(s) being moderated (Edwards \& Lambert, 2007; Hayes, 2013; Preacher et al., 2007). In this paper, conditional indirect effect or moderated mediation is characterized as a model in which the indirect effect of PSS on MAch through M is moderated by V (gender), as is the direct effect of PSS on MAch. In simple terms the path from the intervention (here, perceived social support) to the mediator(s) (i.e., PSS $\rightarrow$ VM or LM; motivational beliefs in this case) as well as the direct effect depends on the level of a third variable $\mathrm{V}$ (gender in this case), whereas the effect of the mediator on the outcome (i.e., VM/LM $\rightarrow$ MAch: mathematics achievement in this study) is constant controlling for parental education, students' long-term educational aspirations and weekly time spent on mathematics homework. This has been described by Edwards and Lambert (2007, p. 10) as "First Stage and Direct effect Moderation Model". It is a conditional process model because it involves moderation and mediation processes (Hayes \& Preacher, 2013). Using the concept and approach discussed in (Edwards \& Lambert, 2007; Hayes, 2015; Preacher \& Hayes, 2008; Preacher et al., 2007) the conditional indirect effect of PSS on achievement through value mathematics (VM) or like mathematics (LM) (Fig. 6.1) are presented as simple slopes as:

$\omega=b_{1} *\left(a_{11}+a_{31} *\right.$ gender $)=a_{11} b_{1}+a_{31} b_{1} *$ gender for value mathematics, and $\omega=b_{2} *\left(a_{12}+a_{32} *\right.$ gender $)=a_{12} b_{2}+a_{32} b_{2} *$ gender for like mathematics.

The conditional indirect effect is quantified by Hayes (2015) as $\mathrm{a}_{31} \mathrm{~b}_{1}$ through SVM and $\mathrm{a}_{32} \mathrm{~b}_{2}$ through SLM and is called the index of moderated mediation (MM) - which is a direct quantification of the linear association between the indirect effect and the putative moderator of that effect (Hayes, 2015, p. 3). Hayes (2015) indicated that for dichotomous moderator, the index of $\mathrm{MM}$ is a test of equality or difference of the conditional indirect effects in the two groups (here between male and female).

Similarly the conditional direct effect PSS on MAch or moderated mediation is presented as a simple slope as: MAch $=c_{1}+c_{3} *$ gender. Similarly as above, the moderated mediation equates to test of equality or difference of the conditional direct effects in the two groups (between male and female). Specifically, the female conditional indirect effect was subtracted from the male conditional indirect effect as a contrast.

Bootstrapping procedures were used to test the multiple mediation and the moderated mediation (conditional indirect effect) hypotheses. Establishing mediation indicates that the total unconditional path $\left(a_{11} * b_{1}+a_{12} * b_{2}\right)$ in Fig. 6.1b which is the sum of the product of the coefficients $\left(a_{11} * b_{1}\right)$ and $\left(a_{12} * b_{2}\right)$ is statistically 
significant, and establishing moderation mediation indicates that the index of moderation mediation (e.g., $\mathrm{a}_{31} \mathrm{~b}_{1}$ through SVM and $\mathrm{a}_{32} \mathrm{~b}_{2}$ through SLM) or test of equality or difference of the conditional direct effects in the two groups (between male and female) are statistically significant.

When the $95 \%$ confidence interval (CI) of the total indirect effect does not include zero, then it is assumed that motivational beliefs mediate the relationship between PSS and achievement. Furthermore, when the $95 \%$ confidence interval of the index of moderated mediation does not include zero, then the conclusion is that the (in)direct effects at various levels of the moderator are statistically significantly different. Subsequently, the type of mediation will be based on the direct effect $\left(\mathrm{c}^{1}\right)$ being significant and positive (i.e., complementary or partial mediation), negative (competitive or inconsistent mediation), or not significant (i.e., indirect-only or full mediation) (Little, Card, Bovaird, Preacher, \& Crandall 2007; Zhao, Lynch, \& Chen, 2010). The analysis was done separately for each perceived support unit.

To ascertain the model fit, several model fit indices were consulted with emphasis placed on the comparative fit index (CFI), the Tucker-Lewis index (both normed along a 0 -to- 1 continuum with values greater than 0.90 reflecting acceptable fit to the data), the root-mean-square error of approximation (RMSEA; values less than 0.08 are indicative of an acceptable fit $)$ and the chi-square test statistic $\left(\chi^{2}\right.$ : for informative purposes only because of its sensitivity to large sample size) (West, Taylor, \& Wu, 2012). Also the differences in model fit between the less and the more constrained models in the model series test should be negligible (e.g., $\triangle \mathrm{CFI}<0.01 ; \triangle \mathrm{RMSEA}$ $<0.015$ ) (Chen, 2007; Cheung \& Rensvold, 2002). Moreover, the final or preferred model should be substantive and meaningful.

\subsection{Results}

We began our evaluation of model fit by considering our measurement or standard model. Goodness-of-fit related to the four-factor model $\left(\chi^{2}{ }_{(145)}=6523.192 ; \mathrm{CFI}=\right.$ $0.922 ; \mathrm{TLI}=0.909 ; \mathrm{RMSEA}=0.034$ ) exhibited an exceptionally good fit to the data. Multi-group CFA was used to examine whether the measurement model is invariant across groups (e.g., the five countries here), whereas multi-group SEM was used to examine whether the mediational model is invariant across the five educational system/cultures. For the measurement model, the configural and metric invariance models were compared across the groups. There was support for the configural $\left(\chi^{2}{ }_{(725)}=8078.600 ; \mathrm{CFI}=0.919 ; \mathrm{TLI}=0.905 ; \mathrm{RMSEA}=0.036\right)$ and factor loading $\left(\chi^{2}{ }_{(785)}=8451.272 ; \mathrm{CFI}=916\right.$; TLI $=0.909$; RMSEA $\left.=036\right)$ invariance. Moreover, the small change in fit index $(\triangle \mathrm{RMSEA}=0.000 ; \Delta \mathrm{CFI}=0.003)$ between the two models across countries also indicated that the factor loadings are equally held across the groups. In all subsequent analysis the factor loadings were held to be equal across the five educational systems or cultures.

We began our detailed analysis by examining the relationship amongst our variables. As can be seen in Table 6.2, there was a strong relationship between students' 
perceived social support from their teachers and higher motivational beliefs (VM: $r=0.640, p<0.001$; LM: $r=0.674, p<0.001$ ), and this in turn was related to mathematics achievement (VM: $r=0.217, p<0.001$; LM: $r=0.128, p<0.001$ ). There was also positive relationship between perceived parental support and students motivational beliefs, however these relationships were lower (VM: $r=0.214, p<$ 0.001; LM: $r=0.233, p<0.001$ ).

A further look at the individual country correlations showed a different pattern. Expressed in terms of simple association, there was no evidence of a relationship between perceived social support (from parents and teachers) and achievement in Tunisia. No relationships was also found between perceived teacher support and achievement in South Africa. However, ".... lack of correlation does not disprove causation (Bollen, 1989, p. 52)". Our model proposes an indirect effect—one that links PSS to achievement through motivational beliefs. Indirect effects can exist even when there is no evidence of simple association (Hayes, 2009; Pollack, Vanepps, \& Hayes 2012; Rucker, Preacher, Tormala, \& Petty 2011) as such a significant total effect is not a requisite for testing indirect effects (Zhao et al., 2010).

\subsubsection{Overall Population Test of the Hypothesized Model}

In order to examine the potential mechanisms underlying the relations between PPS, motivational beliefs and mathematics achievement, we investigated an unconditional mediation effect model, whereby we hypothesized that motivational belief mediated the relation between PSS and achievement controlling for students' parental education, long-term educational aspirations, and hours spent on homework using the approach discussed in Hayes (2013). The statistical diagram (Fig. 6.2; for the overall sample) shows the parameter estimates. As a prelude to the multiple mediation and moderation analysis, the direct effects of perceived social support on the mediators as well as the direct effects of the mediators on achievement were examined for each of the support sources separately controlling for parental education, long-term educational aspiration and weekly time spent on mathematics homework.

Using the overall sample, the results showed that for the perceived parental support model, parental support had a direct effect on "like" and "value mathematics" but a direct negative effect on mathematics achievement. The mediators significantly predicted mathematics achievement. For teacher support model, teacher support had direct positive effects on "like" and "value mathematics" but a direct negative effect on mathematics achievement. Both mediators had a direct effect on mathematic achievement. Results based on the total sample clearly support the notion that motivational beliefs mediate the relationship between students' perceived social support and achievement. Further discussion of this finding will be presented later. From the parameters estimates, one could see that perceived social support from the teachers plays a unique role in bolstering students' motivation beliefs more than parental support after controlling for parental education, long-term educational aspiration and weekly time spent on mathematics homework. 


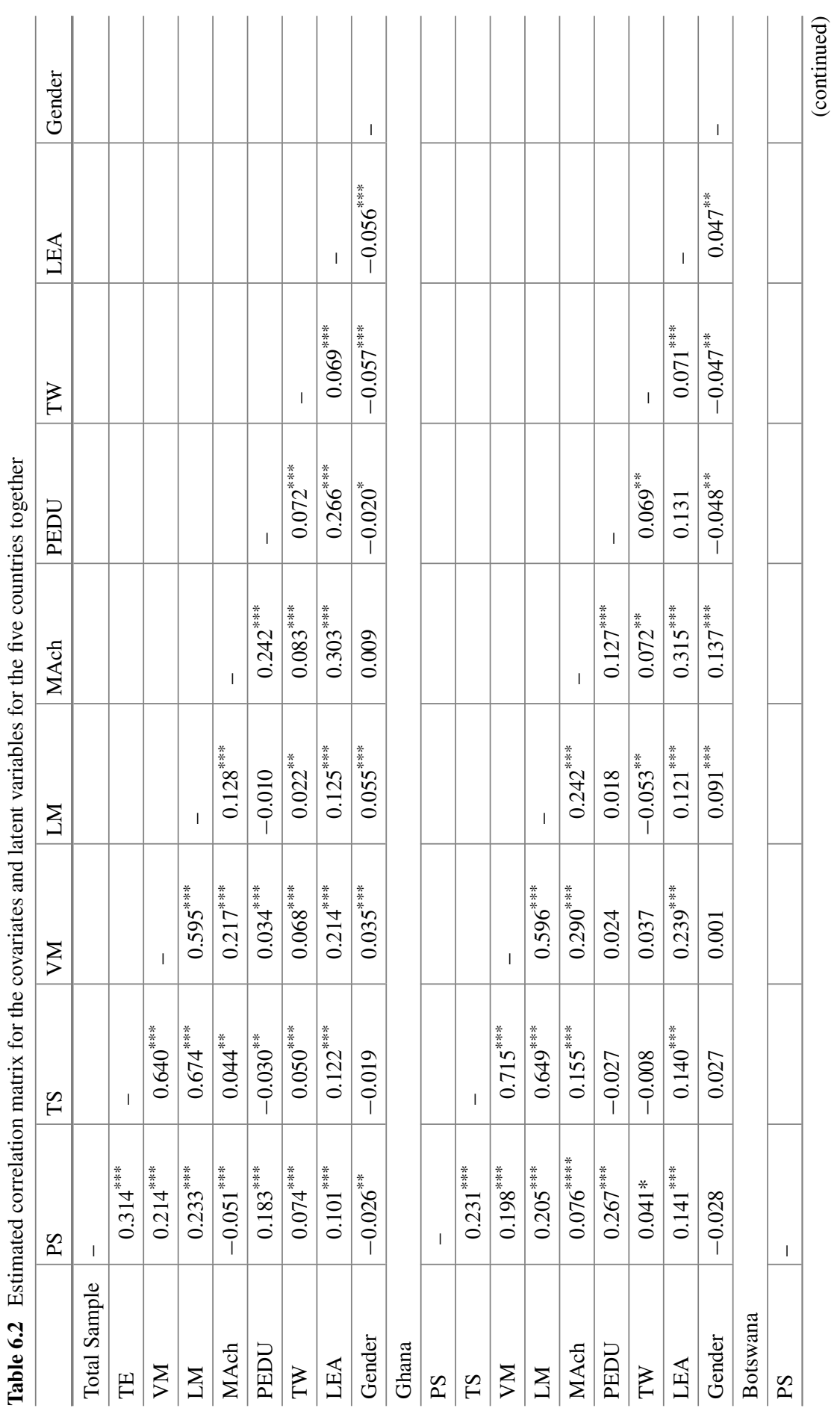




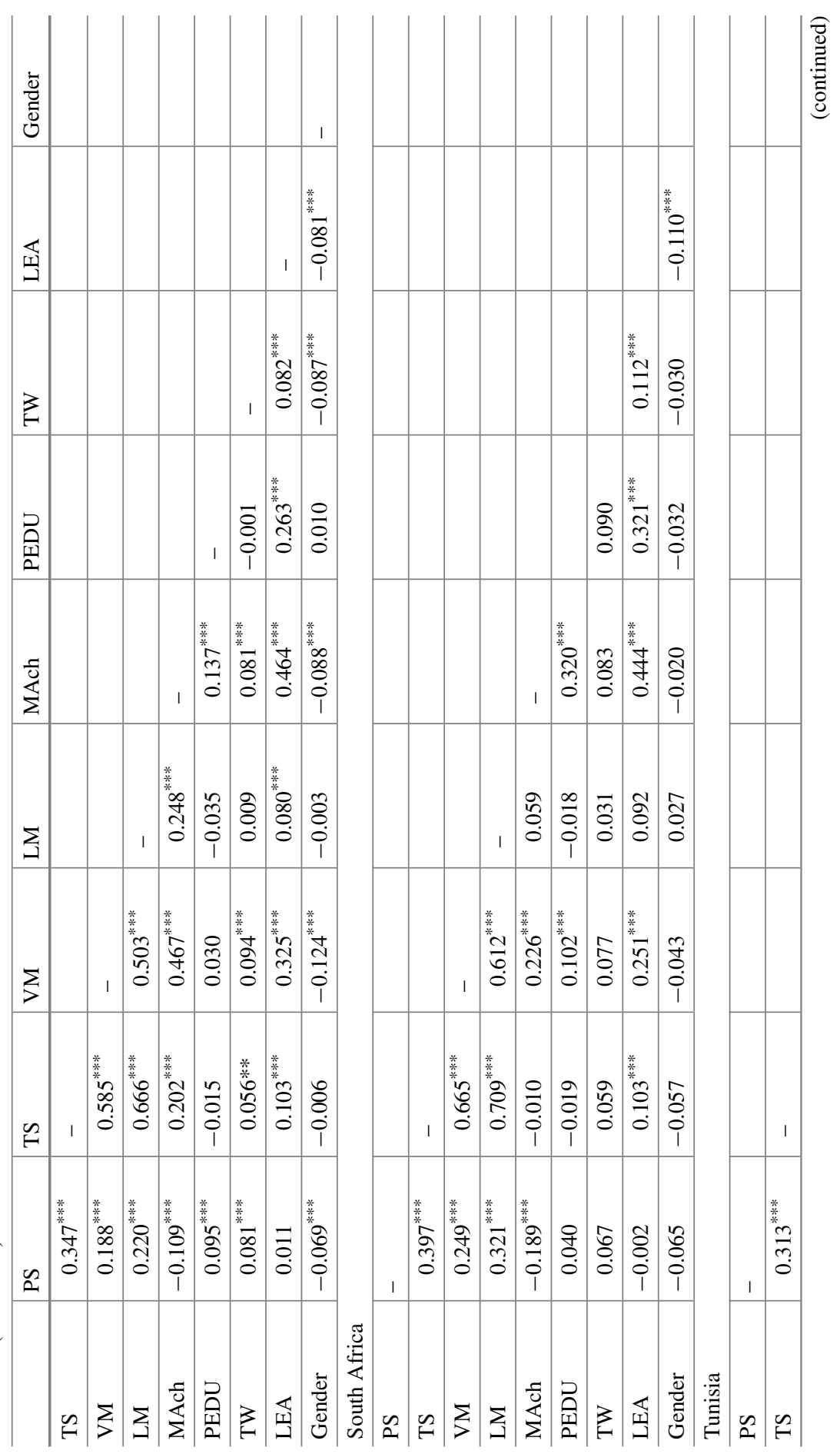




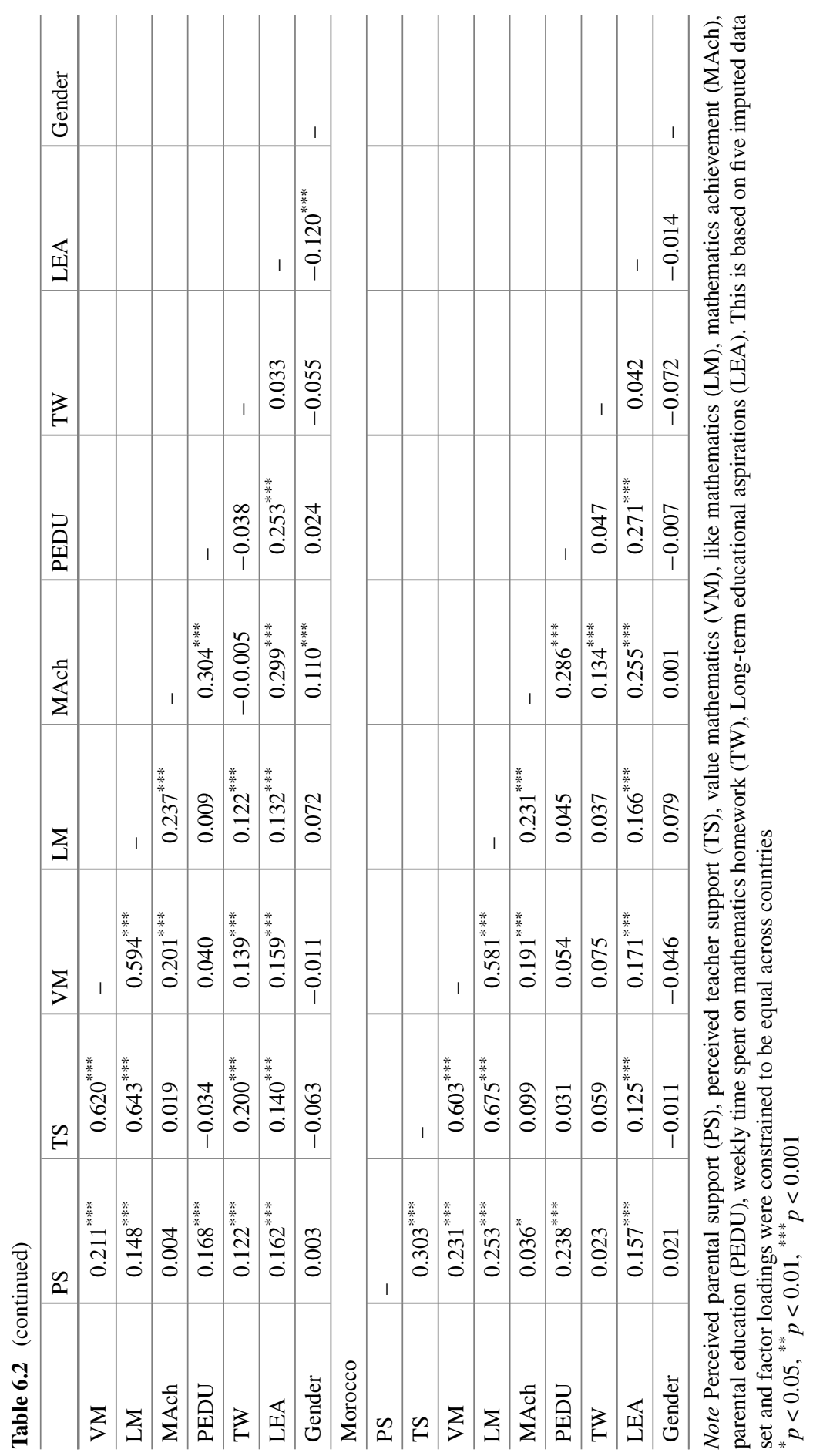



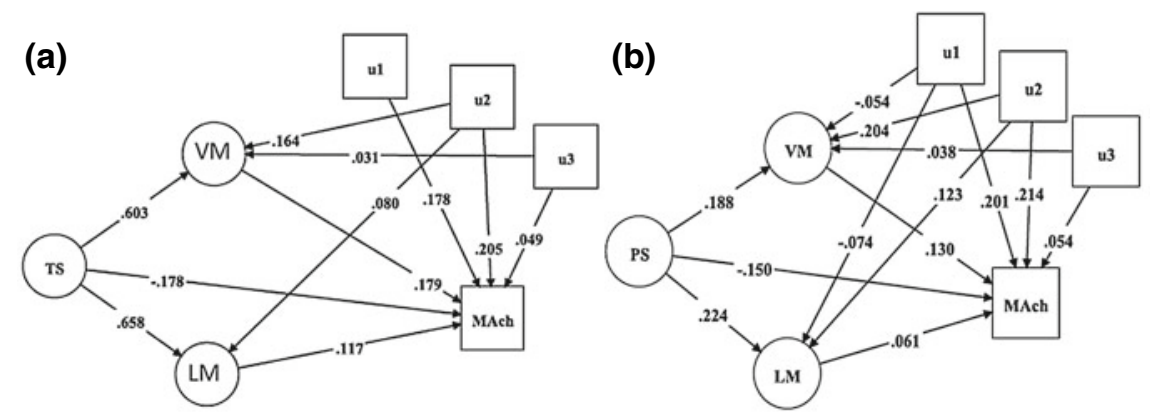

Fig. 6.2 The statistical outcome of the conceptual model using the whole sample. Panel A is the model for the perceived teacher support and panel B is the model for perceived parental support. We allowed the error terms of the two mediators to covary but not shown. PS perceived parental support, $T S$ perceived teacher support, $V M$ value mathematics, $L M$ like mathematics, MAch mathematics achievement. u1-u3 indicates the covariates: parental education (u1), Long-term educational aspirations (u2), weekly time spent on mathematics homework (u3). Estimates are based on five imputed data sets. To reduce visual clutter, only path arrows and statistically significant paths are presented

\subsubsection{Cultural Comparison of the Mediational Model}

We examine whether the mediational model is invariant across the five educational systems by comparing two models for each support source. Comparison was made between two nested models: model with factor loading invariance and path estimates freely estimated and a model with factor loadings and path estimates invariance. For the teacher support model the multi-group equivalence test indicated an acceptable support for the claim of an invariance of the mediational model across countries due to the small change in fit index for the two models ( $\triangle \mathrm{RMSEA}=0.000 ; \triangle \mathrm{CFI}$ $=0.002)$. Similar outcome was achieved for the perceived parental support model $(\triangle \mathrm{RMSEA}=0.000 ; \Delta \mathrm{CFI}=0.005)$. In brief, the multi-group cultural equivalence tests show acceptable support for our hypothesized mediational model. However, a closer look at the parameter values of the paths estimates indicated a wide variation in the parameter estimates across countries. It is therefore advisable to investigate our hypothesized model for each country separately. However this analysis was based on the fact that factor loadings were constrained to be equal across country. Figure 6.3 is the outcome for the parental support model whereas Fig. 6.4 is for the teacher support model.

\subsubsection{Mediation Model Across Country}

As shown in Table 6.3, in all countries, the total indirect effect (i.e., unconditional mediation effect) was statistically significant with a $95 \%$ bias corrected bootstrap 


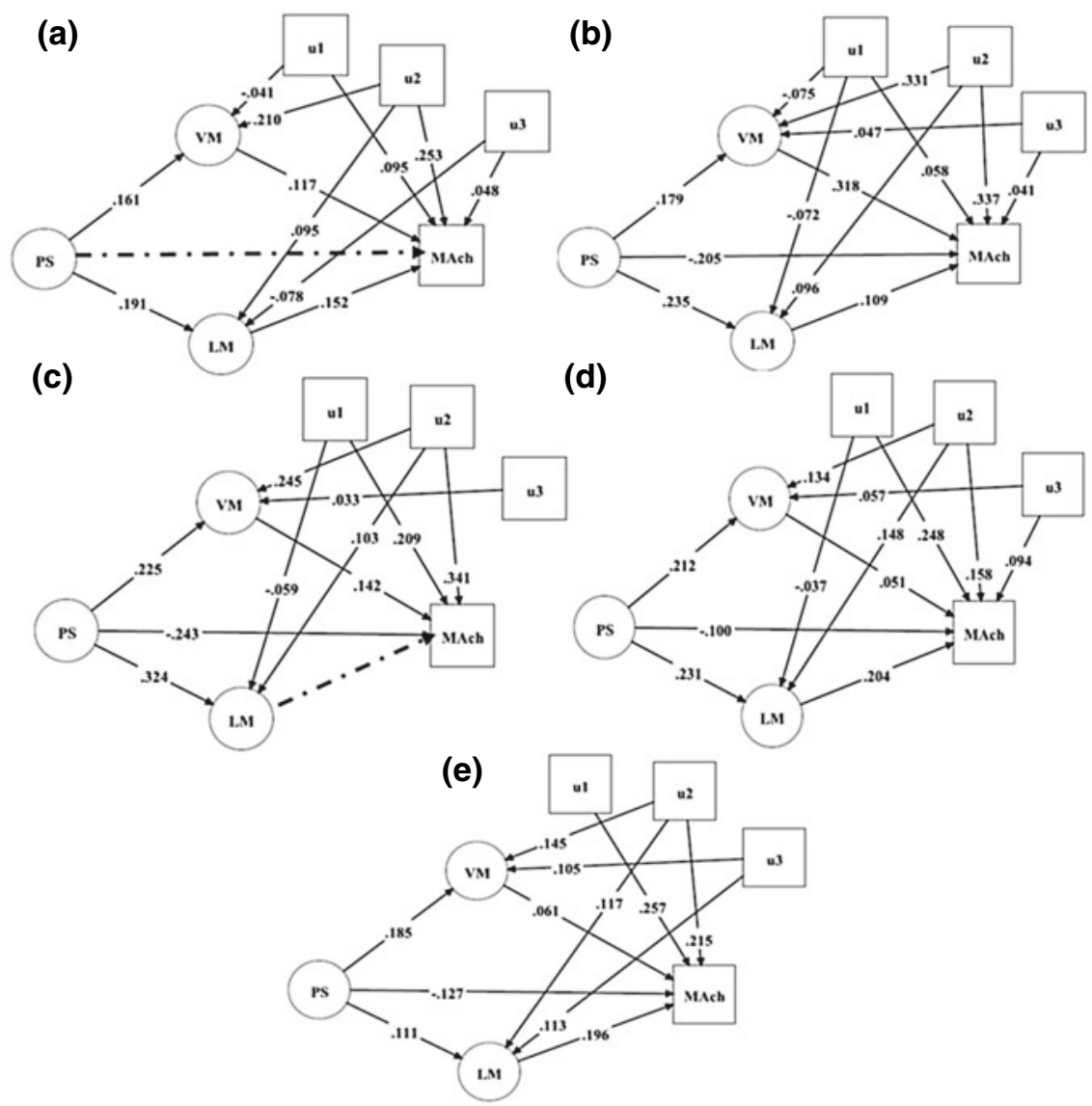

Fig. 6.3 is the statistical outcome of the conceptual model perceived parental support for each country (Model in Fig. 6.1a). Panel A, B, C, D and E are for Ghana, Botswana, South Africa, Morocco and Tunisia respectively. We allowed the error terms of the two mediators to covary but not shown. $P S$ perceived parental support, $V M$ value mathematics, $L M$ like mathematics, MAch mathematics achievement. u1-u3 indicates the covariates: parental education (u1), Long-term educational aspirations (u2), weekly time spent on mathematics homework (u3). Estimates are based on five imputed data sets. To reduce visual clutter, only path arrows and significant path for the covariates are shown. The dash line is a non-significant path

confidence interval. This indicates that, as a set students' motivational belief significantly mediates the relation between PSS and achievement holding constant parental education, weekly time spent on mathematics homework, and students' long-term educational aspirations. Specific indirect effect through "like mathematics" and value mathematics for the two support sources were statistically different from zero except in South Africa that the specific indirect effect of the parental support through "like mathematics" was not statistically different from zero. For the two-support source, PSS predicted students' motivational belief. On the relationship between the media- 


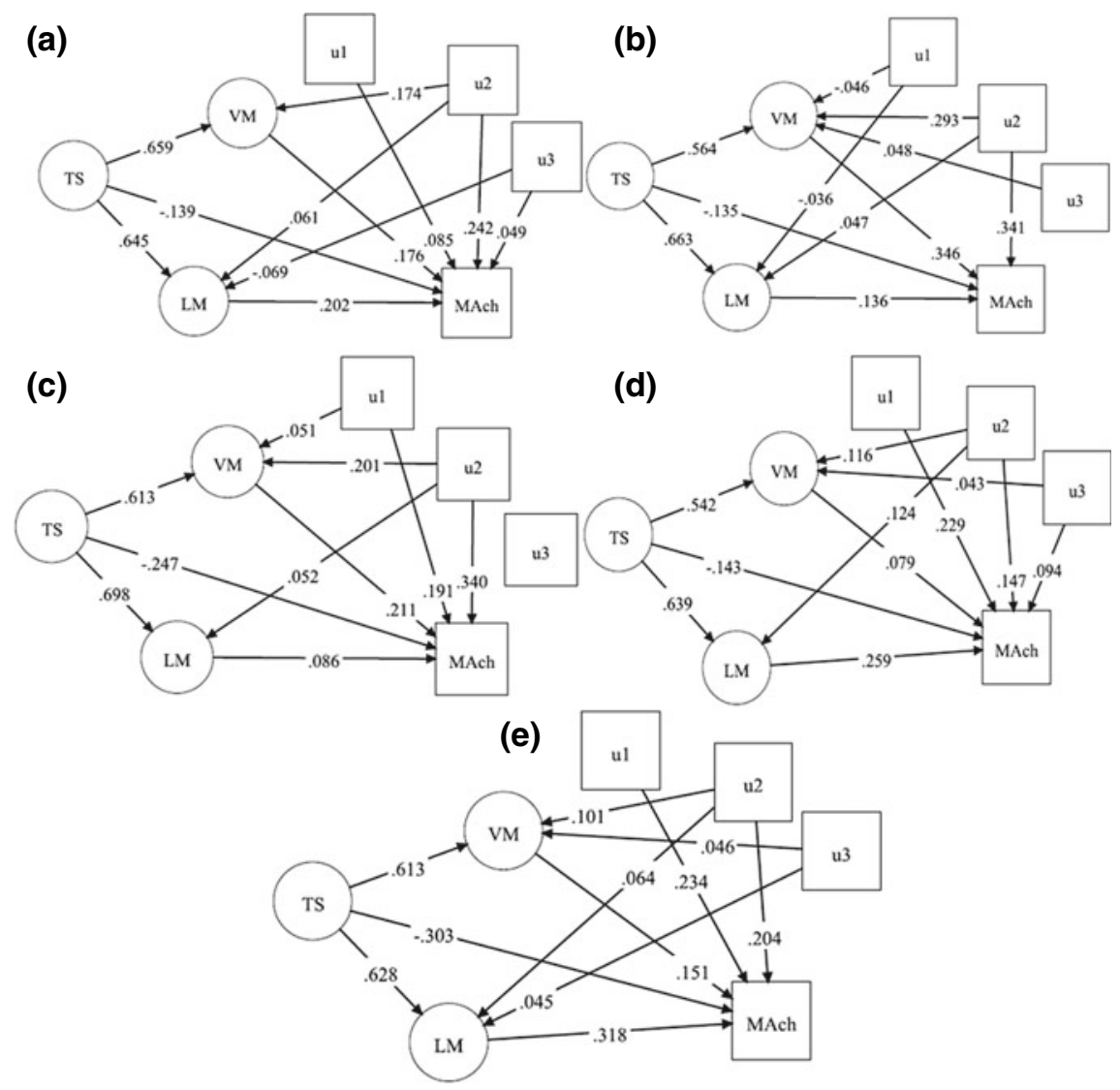

Fig. 6.4 The statistical outcome of the conceptual model perceived teacher support for each country (Model from Fig. 6.1b). Panel A, B, C, D and E are for Ghana, Botswana, South Africa, Morocco and Tunisia respectively. To reduce visual clutter, only path arrows appear and significant path for the covariates are shown. We allowed the error terms of the two mediators to covary but not shown. $T S$ perceived teacher support, $V M$ value mathematics, $L M$ like mathematics, MAch mathematics achievement. u1-u3 indicates the covariates: parental education (u1), Long-term educational aspirations (u2), weekly time spent on mathematics homework (u3). Estimates are based on five imputed data sets

tors and achievement, both mediators positively significantly predicted achievement in all the countries. The parameter estimates from all the countries indicates that perceived social support from the teachers is an important predictor of students' motivation beliefs more than parental support after controlling for parental education, long-term educational aspiration and weekly time spent on mathematics homework.

Further pairwise contrast (see Table 6.3) on the magnitude of the indirect effect indicated that, in the perceived parental support model the two indirect effects for Ghana and Tunisia cannot be distinguished in terms of magnitude, but in Botswana, Morocco and South Africa the indirect effect differ significantly in magnitude for the 


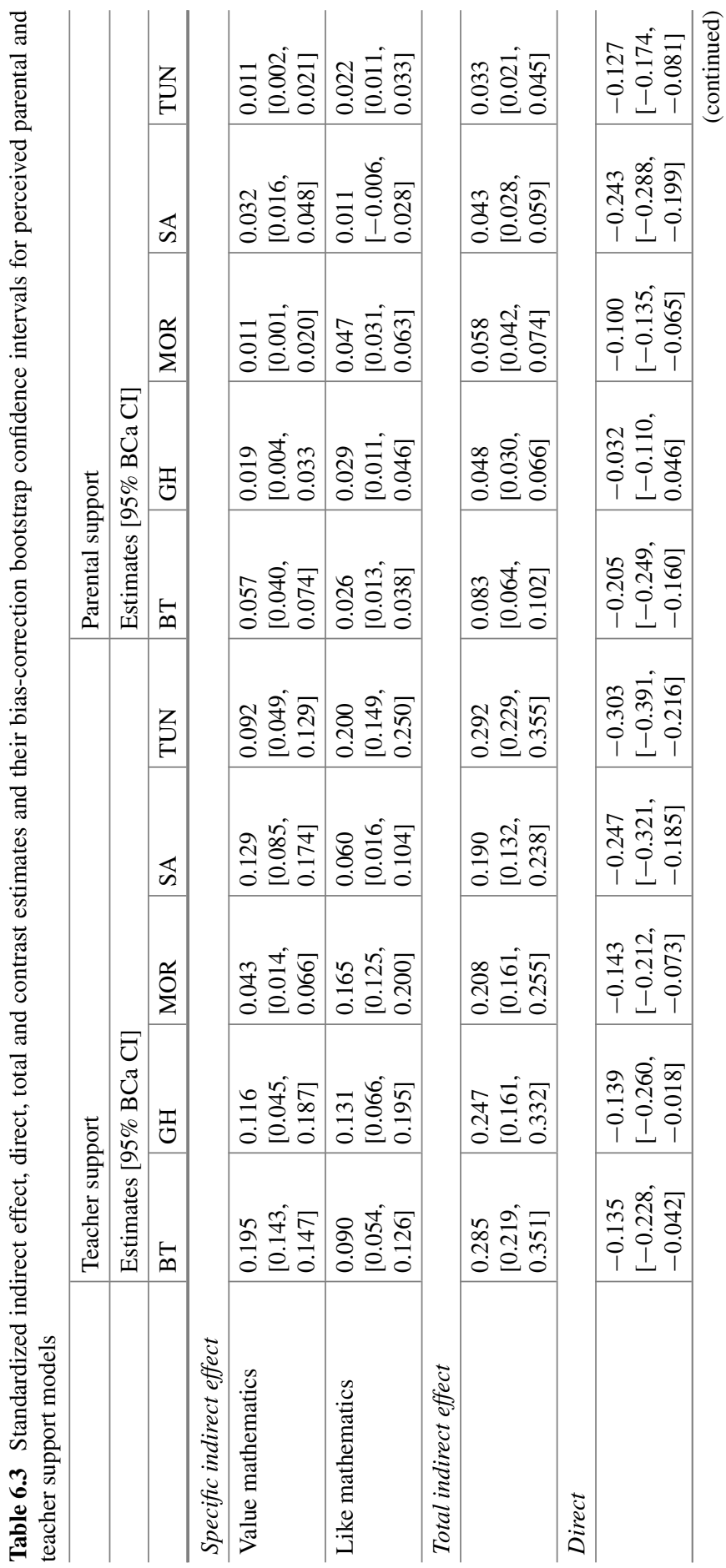


6 Perceived Social Support Network and Achievement: Mediation ...

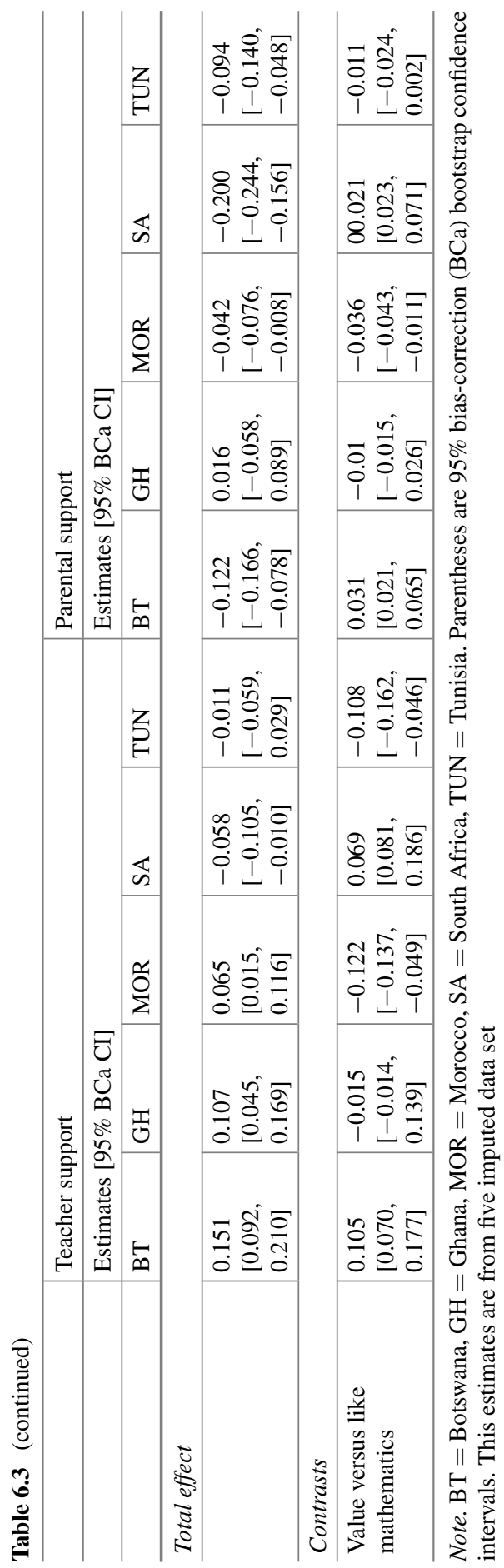


two motivational measures. For the perceived teacher support model, the magnitude of the indirect effect differ significantly across all countries except in the case of Ghana where the contrast comparison indicated that the magnitude of the indirect effect cannot be distinguished in terms of magnitude.

A further examination of the direct effect and total indirect effect for each country indicated an interesting scenario. With the perceived teacher support, holding the mediators constant and controlling for parental education, weekly time spent on mathematics homework, and students' long-term educational aspirations, the direct effect was significant but negative for all the countries.

However, the magnitude of the direct effect was found to be greater than the total effect (except Botswana). Also for Botswana, the mediated effect and direct effect were statistically significant but point in opposite directions. The indirect effect was statistically significant and positive whereas the direct effect was negative and statistically significant. These scenarios are known in the literature as competitive or inconsistent mediation or a mediation with a suppression effect (Little et al., 2007; Zhao et al., 2010)_ “a variable which increases/decreases the predictive validity of another variable (or set of variables) by its inclusion in a regression equation" (Conger, 1974, pp. 36-37) where predictive validity is assessed by the magnitude of the regression coefficient (MacKinnon, Krull, \& Lockwood, 2008, p. 175). The possible reason for this phenomenon is that students' motivational belief suppresses the irrelevant variance in perceived social support, thus allowing for an increased relationship between perceived social support and achievement.

However, in some situations of inconsistent mediation the total effect (sum of the direct and total indirect effects) may be attenuated despite the significance of the direct and indirect paths, because these effects mathematically cancel one another out. This was true in our perceived teacher support model for Tunisia, where the sign of the direct effect was negative and statistically significant (estimate $=-0.303$, $95 \% \mathrm{CI}[-0.391,-0.216])$ and a significant positive total indirect effect (estimate $=$ $0.292,95 \%$ CI $[0.229,0.355])$, but as a result of their opposite signs, the total effect was close to zero (estimate $=-0.0011,95 \%$ CI $[-0.059,0.036])$. Similar scenario was found in Ghana for the parental support model (see Table 6.2).

In the perceived parental support model, similar scenarios of mediation with suppressor effect were found for the Tunisia, Morocco, South Africa, and Botswana. However, the motivational belief measures fully mediated the relationships between parental support and achievement in Ghana for the perceived parental support model. In summary, including the motivational beliefs measures in the model nevertheless improved the overall prediction by effectively removing the measurement artifact variance associated with the perceived support source, thereby making them purer and thus more effective predictors of mathematics achievement. This indicates that although the motivational belief measures act as suppressor variables in essence, these variables suppress irrelevant variance in the PSS measure. Thus, on the contrary, students' motivational beliefs are actually important because they improve the prediction of the students' perceived social support. 


\subsubsection{Moderated Mediation Models Across Country}

The hypothesis that the relation between PSS and achievement via motivational belief is condition on students' gender was examined using moderated mediation analyses otherwise known as conditional process analysis (Hayes \& Preacher, 2013). The goal is to test the conditional direct and indirect effect(s) of PSS on achievement at values of the moderator; male or female. Latent moderated structural equations (LMS) approach was used to estimates the interaction effects.

Using the approach discussed in (Edwards \& Lambert, 2007; Preacher \& Hayes, 2008; Preacher et al., 2007), for the perceived teacher support model (see Table 6.4), the index of MM was statistically significant for the indirect effect through value mathematics for Botswana, South Africa, and Morocco. This indicates that the indirect effect through value of mathematics is moderated by students' gender in Botswana, South Africa, and Morocco with the effect higher for males in these countries. For the indirect effect via "like mathematics", the index of MM was not statistically significant in all the countries indicating that the indirect effect via "like mathematics" does not differ between males and females in those countries.

Differences in these effects are depicted as simple slopes in Fig. 6.5, panlels A through B for males and females. Figure 6.5a shows that, gender moderated each path of the mediated model relating perceived teacher support (factor mean set at default of 0 ), value mathematics, and achievement, such that the indirect effect relating perceived teacher support through value mathematics were stronger for girls when teacher support is lower and stronger for boys when teacher support is higher Morocco, South Africa, and Botswana. On the other hand, the indirect effect of teacher support through "like mathematics" was higher for boys when teacher support is lower and higher for girls when teacher support was higher in Tunisia and Morocco.

\subsection{Discussion}

In the present investigation, we examined the mediational roles of motivational beliefs ("like" and "value mathematics") in relation with the association between perceived social support (PSS: from parents and teachers) and mathematics achievement in an African context. Furthermore, the study examined if the indirect effect of PSS on achievement via motivational belief is contingent on students' gender.

Generally, the results indicated that motivational beliefs taken as a set and individually mediate the effect of PSS on achievement, thereby supporting the multiple mediation model that we proposed. The current results corroborated the results of other studies (Ahmed et al., 2010; Song, Bong, Lee, \& Kim, 2015; Wentzel, 1998) which found that students' motivational beliefs generally serve as an important link between their perceived social support and academic achievement. In general, the analyses support the mediational assumptions in the literature (e.g., Ahmed et al., 


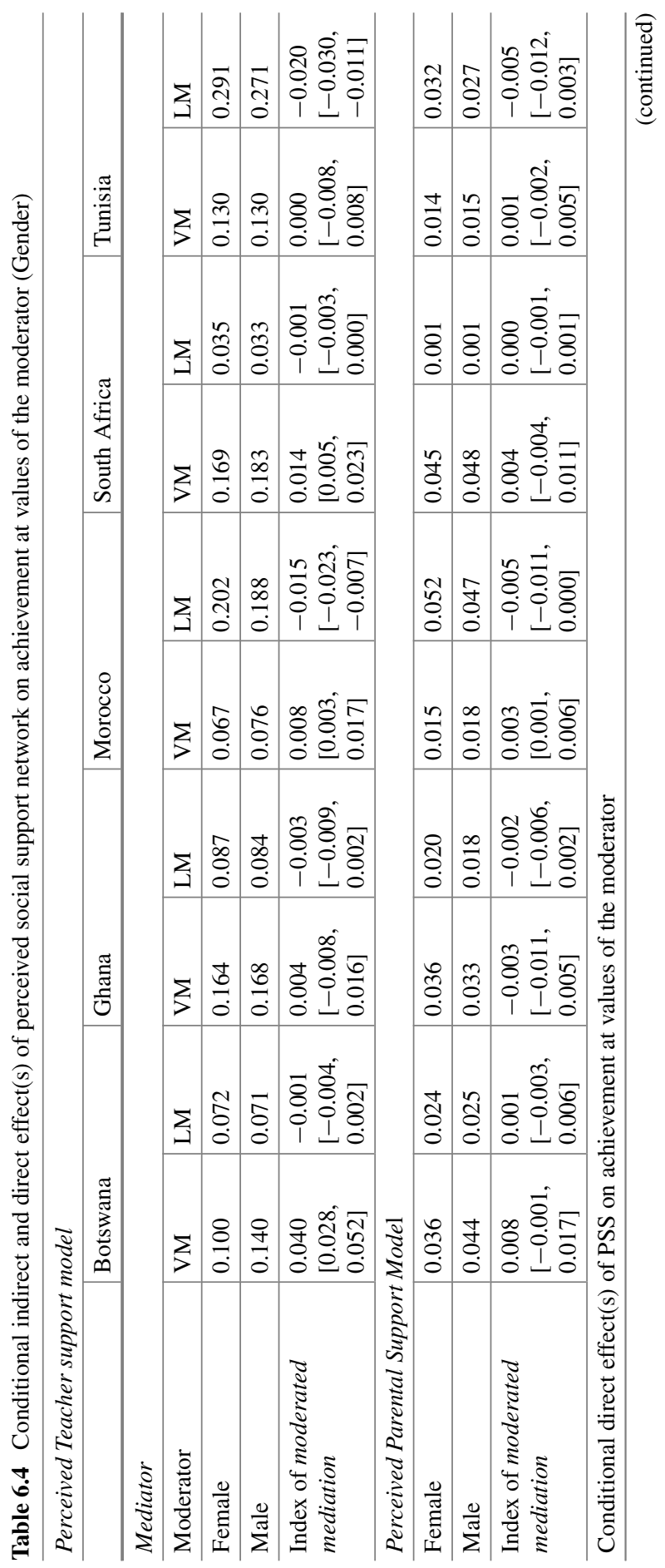




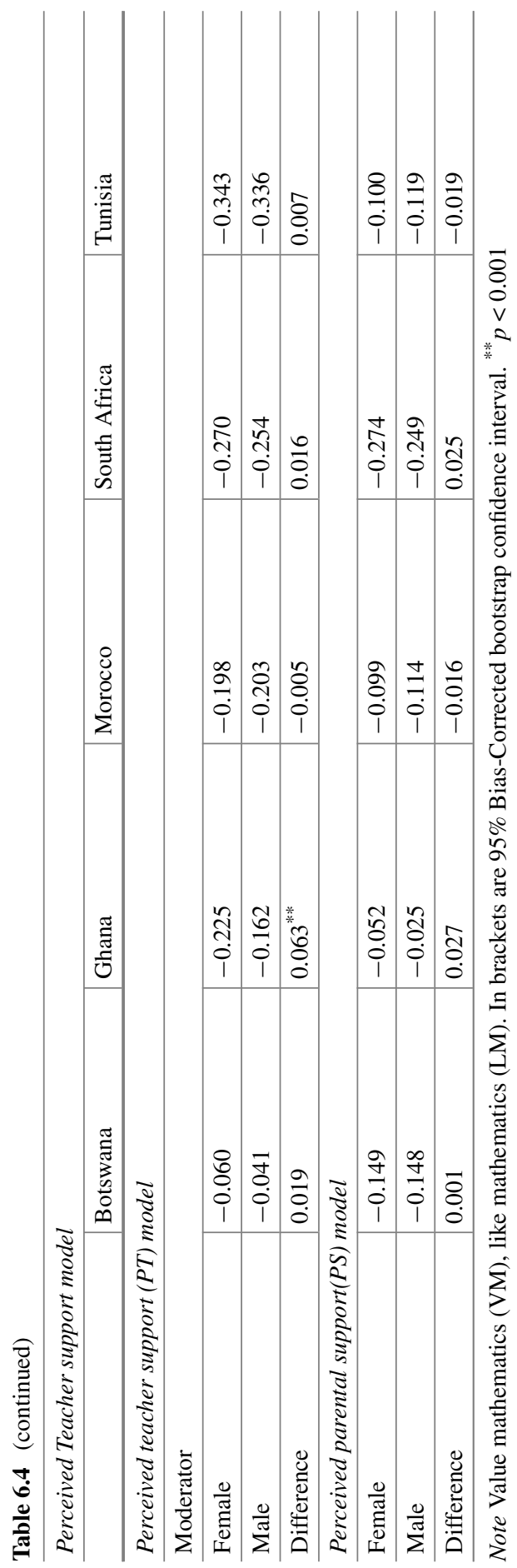


(a)

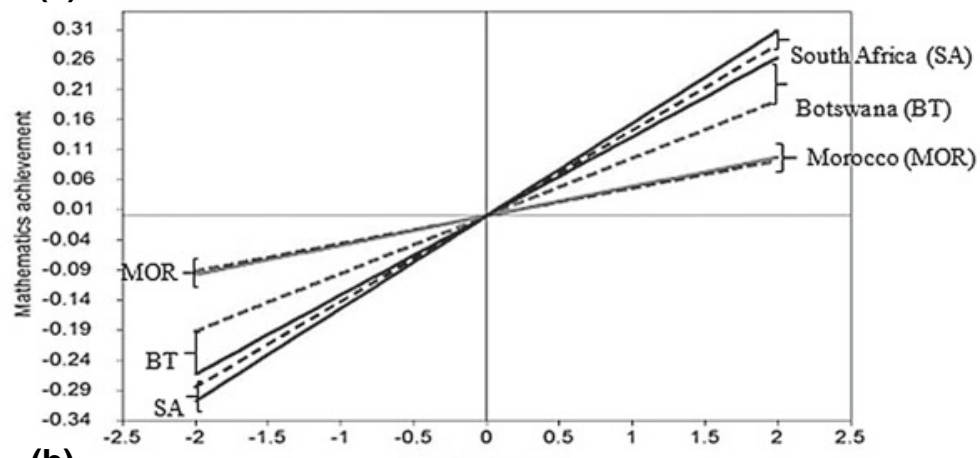

(b)

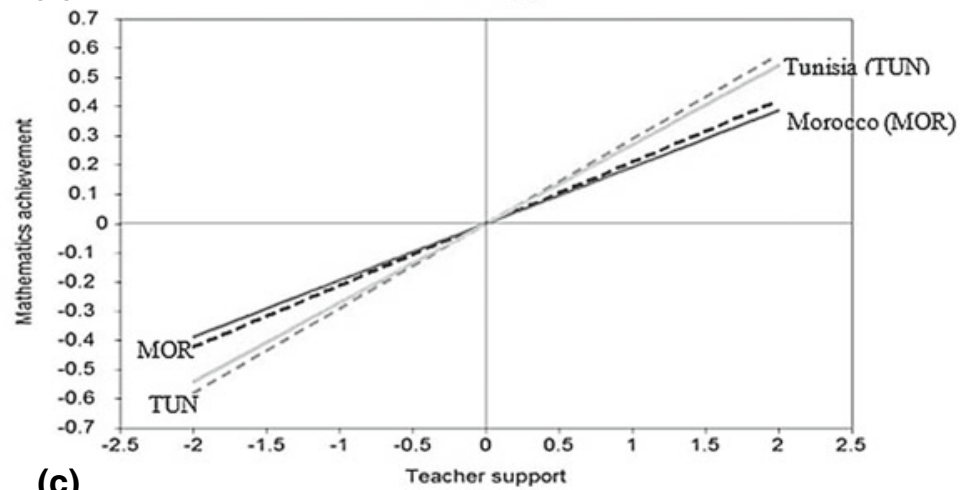

(c)

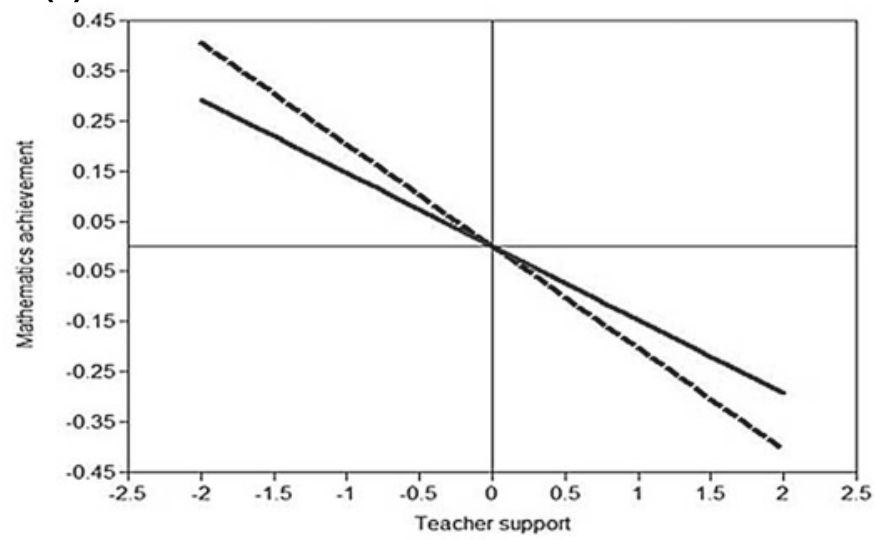

Fig. 6.5 Plots of simple paths conditional indirect model with gender as the moderator variable. In Panels A is the model for the conditional indirect with value mathematics as the mediator and panel B like mathematics as the mediator. Panel C is the direct effect model for Ghana. Dash line (一) is females and continuous lines males. The mean of the perceived teacher support construct was set to zero and plotted between \pm 2 standard deviations of the mean 
2010; Wentzel, 1998). These results, however, refute the long assertion that perceived social support (e.g., from parents) uniquely influences academic performance (e.g., Mackinnon, 2012); rather, the association between perceived social support and achievement is accounted for entirely or partly by how the students value and like mathematics. One important finding from our study was that the mediational hypothesis was supported in all the countries.

The mediation with suppression effect found in the present study indicates that perceived social support from teachers strengthened when students like and understand the importance of mathematics in their life. Inclusion of motivational beliefs improved the prediction power of perceived social support from teachers because the motivational beliefs measures removes any irrelevant artifact variance associated with the perceived teacher support making it "purer" and an absolute predictor of mathematics achievement. Teacher support is beneficial when student like and value mathematics. Similar outcome was witness with the parental support model, however, in Ghana support from parents weakens when students understand the importance of and enjoy mathematics because the relationship between parental support and achievement is completely mediated via students' motivational beliefs. This findings support the notion that parental support has a cultural dimension that transcends geographical boundaries of home and the school (Bofah \& Hannula, 2015). These findings indicate the significant role of perceived social support on students' selfbeliefs and achievement.

Moreover, contrast comparison shows that the magnitude of the indirect effect cannot be distinguished in terms of magnitude in three out of the 10 specific indirect models. Four contrast comparisons indicated that the indirect effect through value of mathematics was stronger whereas three other indirect effect, it was stronger for "like mathematics". This shows the cultural complicity associated with affective measures. The study indicates that perceived social support from the teachers plays a unique role in bolstering students' motivational beliefs (Rueger, Malecki, \& Demaray, 2009; Schneider, Tomada, Normand, Tonci, \& de Domini, 2008) more than parental support, which contradicts studies that support from parents is the most important source of support (Cutrona, Cole, Colangelo, Assouline, \& Russell, 1994).

In respect of gender moderating the indirect effect, the outcomes from this study indicates that the conditional indirect effect of perceived teacher support on achievement through like mathematics is moderated by gender in some countries, contradicting other studies in the literature (e.g., Thomson, Hillman, \& Wernert, 2012). For the conditional indirect effect through value of mathematics the outcome from this study support the literature (Gaspard et al., 2015; Marsh et al., 2005), but the outcome is also dependent on the level of perceived teacher support. However, this conclusion has a culture dimension. The varying gender differences across nations support the cultural specificity of gender as a moderator in these relations (Bofah \& Hannula, 2015; Hyde \& Mertz, 2009; Forgasz et al., 2015). The outcome of this study can influence educational policies on affect and achievement, because the relationship between affect and achievement is the backbone of many affective enhancement programs throughout the world. This is based on the fact that improving affect will lead to achievement and vice versa (Bofah, 2015). 
The results support the motivational and affective significance of social support (e.g., parental support) in students' academic performance (e.g., Rosenfeld et al., 2000). For instance, increasing close contact between teachers and their students would prove beneficial. Schools should also focus on cultivating supportive social relationships between parents and their children and inform parents about the benefits of motivational beliefs such as value and like math in their children's mathematics achievement.

In brief, this study attests to the findings in Rosenfeld et al. (2000), that support reduces uncertainty associated with affect, which then influences school outcomes. Similar models are supported by (Ahmed et al., 2010; Levitt, Levitt, Franco, \& Silver, 1995; Song et al., 2015). Results from this study indicate that educators should work to strengthen students' motivational beliefs so as to shape students' academic performance. For instance, students should receive more information and counselling about mathematics and their future use, which would stimulate their interest in mathematics. Educators should promote more positive affective measures by promoting specific and inclusive self-enhancement strategies to create a supportive and more effective teaching/learning environment for all students in an effort to improve school outcomes.

Some limitations should be considered when interpreting the results. First, data were based on self-report, and thus suffer the limitations associated with all selfreported data. Second, data were cross-sectional, so analyses cannot provide a causal interpretation which requires longitudinal data. Third limitation is that social support from peers was not measured.

Despite these limitations, this study makes significant contributions to the existing research in a number of ways. First, this study expands our understanding of the interplay between perceived social support and motivational beliefs in predicting achievement as well as the role of gender in that effect. This finding of a synergistic role of motivational belief in the relationship between perceived social support and achievement implies interventions that aim at strengthening motivational beliefs will be effective in promoting educational outcomes. Second, because of the strength of the TIMSS data, it is probably the strongest cross-cultural analysis of the relationship between social support and achievement in the African context.

In conclusion, this study provides a comprehensive view showing the differential roles of motivational beliefs in predicting achievement. It also provides a comprehensive picture showing the differential roles of gender beliefs and their interaction with perceived social support in predicting achievement.

\section{References}

Ahmed, W., Minnaert, A., van der Werf, G., \& Kuyper, H. (2010). Perceived social support and early adolescents' achievement: The mediational roles of motivational beliefs and emotions. Journal of Youth and Adolescence, 39(1), 36-46. https://doi.org/10.1007/s10964-008-9367-7.

Bofah, E. A. (2015). Reciprocal determinism between students' mathematics self-concept and achievement in an African context. In K. Krainer \& N. Vondrová (Eds.), CERME 9-Ninth Congress 
of the European Society for Research in Mathematics Education (pp. 1688-1694). Prague, Czech Republic. Retrieved from https://hal.archives-ouvertes.fr/hal-01287995/.

Bofah, E. A. (2016). A cross-cultural analysis of the dimensions of mathematics-related affect: Assessing the psychometric properties and the relationship with achievement (University of Helsinki, Department of Education, Research Report No. 390). University of Helsinki, Helsinki, Finland. Retrieved from https://helda.helsinki.fi/handle/10138/161278.

Bofah, E. A., \& Hannula, M. S. (2015). TIMSS data in an African comparative perspective: Investigating the factors influencing achievement in mathematics and their psychometric properties. Large-Scale Assessments in Education, 3(1), 4. https://doi.org/10.1186/s40536-015-0014-y.

Bollen, K. A. (1989). Structural equations with latent variables. Wiley series in probability and mathematical statistics. New York, NY: Wiley.

Bronfenbrenner, U. (1979). The ecology of human development: Experiments by nature and design. Cambridge, MA: Harvard University Press.

Bronfenbrenner, U. (1986). Ecology of the family as a context for human development: Research perspectives. Developmental Psychology, 22(6), 723-742. https://doi.org/10.1037/0012-1649.22. 6.723 .

Byrne, B. M. (2010). Structural equation modeling with AMOS: Basic concepts, applications, and programming (3rd ed.). New York: Routledge. http://doi.org/10.4324/9781410600219.

Chaman, M. J. M., Beswick, K., \& Callingham, R. (2014). Factors influencing mathematics achievement among secondary school students: A review. In N. Fitzallen, R. Reaburn, \& S. Fan (Eds.), The future of educational research: Perspectives of beginning researchers (Vol. 37, pp. 227-238). Rotterdam, The Netherlands: Sense Publishers. http://doi.org/10.1007/978-94-6209-512-0_19.

Chen, F. F. (2007). Sensitivity of goodness of fit indexes to lack of measurement invariance. Structural Equation Modeling: A Multidisciplinary Journal, 14(3), 464-504. https://doi.org/10.1080/ 10705510701301834.

Cheung, G. W., \& Rensvold, R. B. (2002). Evaluating goodness-of-fit indexes for testing measurement invariance. Structural Equation Modeling: A Multidisciplinary Journal, 9(2), 233-255. https://doi.org/10.1207/S15328007SEM0902_5.

Chiu, M. M., \& Chow, B. W. Y. (2010). Culture, motivation, and reading achievement: High school students in 41 countries. Learning and Individual Differences, 20(6), 579-592. https://doi.org/ 10.1016/j.lindif.2010.03.007.

Conger, A. J. (1974). A revised definition for suppressor variables: A guide to their identification and interpretation. Educational and Psychological Measurement, 34, 35-46. https://doi.org/10. 1177/001316447403400105.

Cutrona, C. E., Cole, V., Colangelo, N., Assouline, S. G., \& Russell, D. W. (1994). Perceived parental social support and academic achievement: An attachment theory perspective. Journal of Personality and Social Psychology, 66(2), 369-378. https://doi.org/10.1037//0022-3514.66.2. 369.

Eccles, J. S. (2007). Families, schools, and developing achievement-related motivations and engagement. In J. E. Grusec \& P. D. Hastings (Eds.), Handbook of socialization (pp. 665-691). New York, NY: The Guilford Press.

Eccles, J. S. (2009). Who am I and what am I going to do with my life? Personal and collective identities as motivators of action. Educational Psychologist, 44(2), 78-89. https://doi.org/10. 1080/00461520902832368.

Eccles, J. S., Adler, T. F., Futterman, R., Goff, S. B., Kaczala, C. M., Meece, J. L., et al. (1983). Expectations, values, and academic behaviors. In J. T. Spence (Ed.), Achievement and achievement motives: Psychological and sociological approaches (pp. 76-146). San Francisco, CA: W. H. Freeman and Company.

Eccles, J., Wigfield, A., Harold, R. D., \& Blumenfeld, P. (1993). Age and gender differences in children's self- and task perceptions during elementary school. Child Development, 64(3), 830-847. https://doi.org/10.2307/1131221.

Edwards, J. R., \& Lambert, L. S. (2007). Methods for integrating moderation and mediation: A general analytical framework using moderated path analysis. Psychological Methods, 12(1), 1-22. https://doi.org/10.1037/1082-989X.12.1.1. 
Forgasz, H., Leder, G., Mittelberg, D., Tan, H., \& Murimo, A. (2015). Affect and gender. In B. Pepin \& B. Roesken-Winter (Eds.), From beliefs to dynamic affect systems in mathematics education (pp. 245-268). Cham, Switzerland: Springer. http://doi.org/10.1007/978-3-319-06808-4_12.

Foy, P., Brossman, B., \& Galia, J. (2013). Scaling the TIMSS and PIRLS 2011 achievement data. Chestnut Hill, MA. Retrieved from http://timssandpirls.bc.edu/methods/index.html.

Frenzel, A. C., Pekrun, R., \& Goetz, T. (2007). Girls and mathematics-A "hopeless" issue? A control-value approach to gender differences in emotions towards mathematics. European Journal of Psychology of Education. http://doi.org/10.1007/BF03173468.

Gaspard, H., Dicke, A. L., Flunger, B., Schreier, B., Häfner, I., Trautwein, U., et al. (2015). More value through greater differentiation: Gender differences in value beliefs about math. Journal of educational psychology, 107(3), 663-677. https://doi.org/10.1037/edu0000003.

Gerdes, P. (1998). Culture and mathematics education in (Southern) Africa. In C. Alsina, J. M. Alvarez, B. Hodgson, C. Laborde, \& A. Perez (Eds.), 8th International Congress on Mathematical Education. Selected Lectures (pp. 221-231). Sevilla: S.A.E.M. Thales.

Hayes, A. F. (2009). Beyond Baron and Kenny: Statistical mediation analysis in the new millennium. Communication Monographs, 76(4), 408-420.

Hayes, A. F. (2013). Introduction to mediation, moderation, and conditional process analysis: A regression based approach. New York: The Guilford Press. http://doi.org/978-1-60918-230-4.

Hayes, A. F. (2015). An index and simple test of linear moderated mediation. Multivariate Behavioral Research, 50(1), 1-22. https://doi.org/10.1080/00273171.2014.962683.

Hayes, A. F., \& Preacher, K. J. (2013). Conditional process modeling: Using structural equation modeling to examine contingent causal processes. In G. R. Hancock \& R. O. Mueller (Eds.), Structural equation modeling: A second course (2nd ed., pp. 219-266). Charlotte, NC: Information Age Publishing.

Hyde, J. S., Fennema, E., \& Lamon, S. J. (1990). Gender differences in mathematics performance: A meta-analysis. Psychological Bulletin, 107(2), 139-155.

Hyde, J. S., Lindberg, S. M., Linn, M. C., Ellis, A. B., \& Williams, C. C. (2008). Gender similarities characterize math performance. Science, 321(July), 494-495. https://doi.org/10.1126/science. 1160364.

Hyde, J. S., \& Mertz, J. E. (2009). Gender, culture, and mathematics performance. Proceedings of the National Academy of Sciences of the United States of America, 106(22), 8801-8807. https:// doi.org/10.1073/pnas.0901265106.

Jacobs, J. E., Lanza, S., Osgood, D. W., Eccles, J. S., Wigfield, A., Osgood, W. D., et al. (2002). Changes in children's self-competence and values: Gender and domain differences across grades one through twelve. Child Development, 73(2), 509-527. https://doi.org/10.1111/1467-8624. 00421.

Keith, T. Z. (2015). Multiple regression and beyond: An introduction to multiple regression and structural equation modeling ( 2 nd ed.). New York: Routledge.

Levitt, M. J., Levitt, J. L., Franco, N., \& Silver, M. E. (1995). Social support networks and achievement: The role of network member attitudes. In Paper presented at the Annual Meeting of the American Educational Research Association. San Francisco, CA. Retrieved from http://eric.ed. gov/?id=ED385906.

Little, T. D. (1997). Mean and Covariance Structures (MACS) analyses of cross-cultural data: Practical and theoretical issues. Multivariate Behavioral Research, 32, 53-76.

Little, T. D., Card, N. A., Bovaird, J. A., Preacher, K. J., \& Crandall, C. S. (2007). Structural equation modeling of mediation and moderation with contextual factors. In T. D. Little, N. A. Card, \& J. A. Bovaird (Eds.), Modeling contextual effects in longitudinal studies (pp. 207-230). Mahwah, NJ: Lawrence Erlbaum Associates.

Lubke, G. H., Dolan, C. V., Kelderman, H., \& Mellenbergh, G. J. (2003). On the relationship between sources of within- and between-group differences and measurement invariance in the common factor model. Intelligence, 31(6), 543-566. https://doi.org/10.1016/S0160-2896(03)00051-5.

MacKinnon, D. P., Krull, J. L., \& Lockwood, C. M. (2008). Equivalence of the mediation, confounding and suppression effect. Prevention Science, 1(4), 173-181. https://doi.org/10.1016/j. drugalcdep.2008.02.002.A. 
Mackinnon, S. P. (2012). Perceived social support and academic achievement: Cross-lagged panel and bivariate growth curve analyses. Journal of Youth and Adolescence, 41(4), 474-485. https:// doi.org/10.1007/s10964-011-9691-1.

Marsh, H. W., Abduljabbar, A. S., Abu-Hilal, M. M., Morin, A. J. S., Abdelfattah, F., Leung, K. C., et al. (2013). Factorial, convergent, and discriminant validity of TIMSS math and science motivation measures: A comparison of Arab and Anglo-Saxon countries. Journal of Educational Psychology, 105(1), 108-128. https://doi.org/10.1037/a0029907.

Marsh, H. W., Trautwein, U., Lüdtke, O., Köller, O., \& Baumert, J. (2005). Academic self-concept, interest, grades, and standardized test scores: Reciprocal effects models of causal ordering. Child Development, 76(2), 397-416. https://doi.org/10.1111/j.1467-8624.2005.00853.x.

Meece, J. L., Glienke, B. B., \& Burg, S. (2006). Gender and motivation. Journal of School Psychology, 44(5), 351-373. https://doi.org/10.1016/j.jsp.2006.04.004.

Muthén, L. K., \& Muthén, B. O. (1998). Mplus user's guide (7th ed.). Los Angeles, CA: Muthén and Muthén.

Mutodi, P., \& Ngirande, H. (2014). The influence of students' perceptions on mathematics performance. A case of a selected high school in South Africa. Mediterranean Journal of Social Sciences, 5(3), 431-445. http://doi.org/10.5901/mjss.2014.v5n3p431.

Pollack, J. M., Vanepps, E. M., \& Hayes, A. F. (2012). The moderating role of social ties on entrepreneurs' depressed affect and withdrawal intentions in response to economic stress. Journal of Organizational Behavior, 33, 839-862. https://doi.org/10.1002/job.1794.

Preacher, K. J., \& Hayes, A. F. (2008). Asymptotic and resampling strategies for assessing and comparing indirect effects in multiple mediator models. Behavior Research Methods, 40(3), 879-891. https://doi.org/10.3758/BRM.40.3.879.

Preacher, K. J., Rucker, D. D., \& Hayes, A. F. (2007). Addressing moderated mediation hypotheses: Theory, methods, and prescriptions. Multivariate Behavioral Research, 42(1), 185-227.

Roeser, R. W., Eccles, J. S., \& Sameroff, A. J. (2000). School as a context of early adolescents' academic and social-emotional development: A summary of research findings. The Elementary School Journal, 100(5), 443. https://doi.org/10.1086/499650.

Rosenfeld, L., Richman, J., \& Bowen, G. (2000). Social support networks and school outcomes: The centrality of the teacher. Child and Adolescent Social Work Journal, 17(3), 205-226.

Rubin, D. B. (1987). Multiple imputation for nonresponse in surveys (Vol. 307). New York: Wiley.

Rucker, D. D., Preacher, K. J., Tormala, Z. L., \& Petty, R. E. (2011). Mediation analysis in social psychology: Current practices and new recommendations. Social and Personality Psychology Compass, 5(6), 359-371. https://doi.org/10.1111/j.1751-9004.2011.00355.x.

Rueger, S. Y., Malecki, C. K., \& Demaray, M. K. (2009). Relationship between multiple sources of perceived social support and psychological and academic adjustment in early adolescence: Comparisons across gender. Journal of Youth and Adolescence, 39(1), 47-61. https://doi.org/10. 1007/s10964-008-9368-6.

Ryan, R. M., \& Deci, E. L. (2000). Intrinsic and extrinsic motivations: Classic definitions and new directions. Contemporary Educational Psychology, 25, 54-67. https://doi.org/10.1006/ceps. 1999.1020.

Ryan, R. M., \& Deci, E. L. (2009). Promoting self-determined school engagement: Motivation, learning, and well-being. In K. R. Wentzel \& A. Wigfield (Eds.), Handbook of motivation at school (pp. 171-195). New York: Routledge.

Sass, D. A. (2011). Testing measurement invariance and comparing latent factor means within a confirmatory factor analysis framework. Journal of Psychoeducational Assessment, 29(4), 347-363. https://doi.org/10.1177/0734282911406661.

Schneider, B. H., Tomada, G., Normand, S., Tonci, E., \& de Domini, P. (2008). Social support as a predictor of school bonding and academic motivation following the transition to Italian middle school. Journal of Social and Personal Relationships, 25(2), 287-310. https://doi.org/10.1177/ 0265407507087960.

Singh, K., Granville, M., \& Dika, S. (2002). Mathematics and science achievement: Effects of motivation, interest, and academic engagement. The Journal of Educational Research, 95(6), 323-332. https://doi.org/10.1080/00220670209596607. 
Song, J., Bong, M., Lee, K., \& Kim, S. (2015). Longitudinal investigation into the role of perceived social support in adolescents' academic motivation and achievement. Journal of Educational Psychology, 107(3), 821-841. https://doi.org/10.1037/edu0000016.

Steenkamp, J.-B. E. M., \& Baumgartner, H. (1998). Assessing measurement invariance in crossnational consumer research. Journal of Consumer Research, 25(1), 78-90.

Stromquist, N. P. (2007). Gender equity education globally. In Handbook for achieving gender equity through education (2nd ed., pp. 33-42). Mahwah, NJ: Erlbaum.

Thomson, S., Hillman, K., \& Wernert, N. (2012). Monitoring Australian year 8 student achievement internationally: TIMSS 2011. Camberwell, Victoria, Australia: Australian Council for Educational Research. Retrieved from http://research.acer.edu.au/timss_pirls_2011/1/.

Vandenberg, R. J., \& Lance, C. E. (2000). A review and synthesis of the measurement invariance literature: Suggestions, practices, and recommendations for organizational research. Organizational Research Methods, 3, 4-70. https://doi.org/10.1177/109442810031002.

Watt, H. M. G. (2004). Development of adolescents' self-perceptions, values, and task perceptions according to gender and domain in 7th- through 11th-grade Australian students. Child Development, 75(5), 1556-1574. https://doi.org/10.1111/j.1467-8624.2004.00757.x.

Watt, H. M. G., Shapka, J. D., Morris, Z. A., Durik, A. M., Keating, D. P., \& Eccles, J. S. (2012). Gendered motivational processes affecting high school mathematics participation, educational aspirations, and career plans: A comparison of samples from Australia, Canada, and the United States. Developmental Psychology, 48(6), 1594-1611.

Wentzel, K. R. (1998). Social relationships and motivation in middle school: The role of parents, teachers, and peers. Journal of Educational Psychology, 90(2), 202-209. https://doi.org/10.1037/ 0022-0663.90.2.202.

West, S. G., Taylor, A. B., \& Wu, W. (2012). Model fit and model selection in structural equation modeling. In R. H. Hoyle (Ed.), Handbook of structural equation modeling (pp. 209-231). New York: The Guilford Press.

Wigfield, A., \& Cambria, J. (2010). Students' achievement values, goal orientations, and interest: Definitions, development, and relations to achievement outcomes. Developmental Review, 30(1), 1-35. https://doi.org/10.1016/j.dr.2009.12.001.

Wigfield, A., Eccles, J. S., Yoon, K. S., Harold, R. D., Arbreton, A. J. A., Freedman-Doan, C., et al. (1997). Change in children's competence beliefs and subjective task values across the elementary school years: A 3-year study. Journal of Educational Psychology, 89(3), 451-469. https://doi. org/10.1037/0022-0663.89.3.451.

Zhao, X., Lynch, J. G., Jr., \& Chen, Q. (2010). Reconsidering Baron and Kenny: Myths and truths about mediation analysis. Journal of Consumer Research, 37(2), 197-206. https://doi.org/10. $1086 / 651257$.

Open Access This chapter is licensed under the terms of the Creative Commons Attribution 4.0 International License (http://creativecommons.org/licenses/by/4.0/), which permits use, sharing, adaptation, distribution and reproduction in any medium or format, as long as you give appropriate credit to the original author(s) and the source, provide a link to the Creative Commons license and indicate if changes were made.

The images or other third party material in this chapter are included in the chapter's Creative Commons license, unless indicated otherwise in a credit line to the material. If material is not included in the chapter's Creative Commons license and your intended use is not permitted by statutory regulation or exceeds the permitted use, you will need to obtain permission directly from the copyright holder.

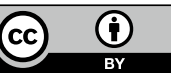

